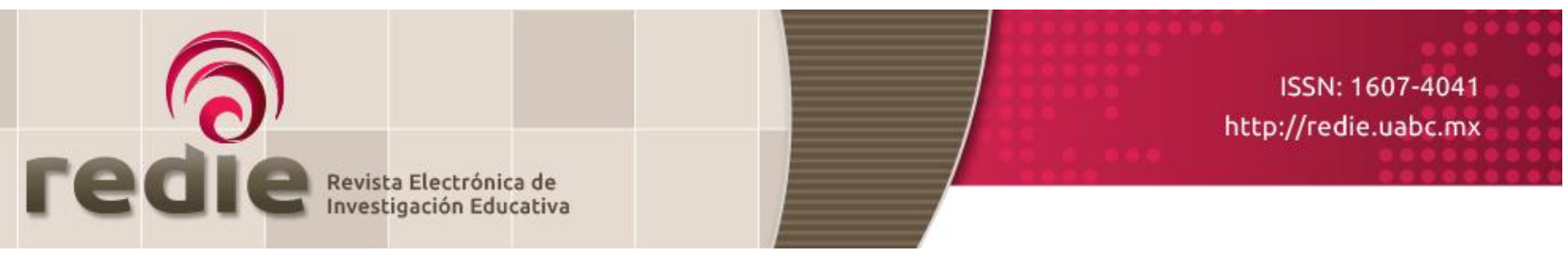

Vol. 20, Núm. 2, 2018

\title{
Escritura argumentativa en enseñanza primaria chilena: un estudio de caso ${ }^{1}$
}

\section{Argumentative Writing in Primary Education in Chile: A Case Study}

\author{
Beatriz Figueroa Sandoval (*) bfiguero@udec.cl \\ Mariana Aillon Neumann $(*)$ maillon@udec.cl \\ Angie Neira Martínez (*) angieneira@udec.cl \\ (*) Universidad de Concepción \\ (Recibido: 22 de noviembre de 2016; Aceptado para su publicación: 3 de enero de 2017)
}

Cómo citar: Figueroa, B., Aillon, M. y Neira, A. (2018). Escritura argumentativa en enseñanza primaria chilena: un estudio de caso. Revista Electrónica de Investigación Educativa, 20(2), 59-68. https://doi.org/10.24320/redie.2018.20.2.1710

\section{Resumen}

El estudio presenta la revisión de comentarios escritos de estudiantes de enseñanza primaria de Hualpén, Chile. El análisis de los discursos considera una aproximación teórica pragma-dialéctica, desde las estrategias usadas por los sujetos (justificativa, polémica y/o deliberativa) y de la red de situación en que se originan las producciones. Esta red comprende tareas de construcciones semióticas, de mundo, de identidad sociocultural, política y de conexión. Los resultados de la investigación describen cómo los niños manejan, por ejemplo, el ensamblaje de dos sistemas semióticos (el lenguaje y las imágenes), construyen su realidad frente a un tema territorial controvertido, toman conciencia de las tensiones sociales generadas, entre otros aspectos. Se destaca cómo, desde una aproximación del lenguaje en uso, es posible generar en los niños una postura crítica respecto a una situación del entorno, movilizándolos naturalmente hacia los inicios de la escritura argumentativa.

Palabras clave: Escritura, argumentación, enseñanza primaria, identidad cultural.

\section{Abstract}

The study presents a review of written comments made by elementary school students in Hualpén, Chile. The discourse analysis uses a pragma-dialectical theoretical approach to strategies used by subjects (justification, polemical and/or deliberative), and the situational network in which the writing was produced. This network includes tasks relating to semiotic construction, the world, sociocultural identity, politics, and connection. The results of the study describe how children handle the assembly of two semiotic systems (language and images), construct their reality in the face of a controversial territorial topic, and become aware of social tensions caused, among other aspects. The research highlights how,

\footnotetext{
1 Esta investigación forma parte del Proyecto Fondecyt Regular No 1140664: "Diseño multimodal en prácticas letradas escolares: avances desde los códigos restringidos a los elaborados", financiado por la Comisión Nacional de Investigación Científica y Tecnológica de Chile (Conicyt).
} 
with a language-in-use approach, it is possible to foster a critical opinion in students regarding their local environment, which guides them naturally towards their first steps in argumentative writing.

Keywords: Writing, argumentation, primary education, cultural identity.

\section{Introducción}

En Chile, las pruebas estandarizadas aplicadas en los últimos años de nivel primaria muestran un avance poco significativo en comprensión lectora y escritura. Por ejemplo, la prueba SIMCE ${ }^{2}$ de 2014 y 2015 (Agencia de la Calidad de la Educación, 2015; 2016) evidencia resultados que no superan el 55\% de los objetivos propuestos en los ítems de escritura. Estos datos dan cuenta de la necesidad de promover en el aula la producción escrita a la par de las prácticas lectoras.

El presente estudio describe las características observadas en un conjunto de textos que dan cuenta del desarrollo de la opinión crítica escrita en un grupo de estudiantes de sexto año de una escuela pública chilena, en la búsqueda de patrones socio-cognitivos que permitan fortalecer la producción de discursos argumentativos en estos niveles.

El trabajo se llevó a cabo en el marco de una investigación mayor, la cual contempló, en una primera etapa, un estudio de las representaciones sociales de los niños de la muestra respecto de su ciudad/comuna con el objetivo de establecer los núcleos culturales más significativos para contextualizar las prácticas de lectura y escritura.

La escuela en cuestión se inserta en una zona industrial que reúne importantes empresas petroquímicas y de acero, las que constituyen una fuente laboral significativa para profesionales, ingenieros, técnicos y obreros calificados de la región. El estudio preliminar de las representaciones sociales de los jóvenes advierte que, no obstante la cercanía de la escuela con el barrio industrial, esta zona no forma parte del núcleo cultural de sus representaciones como era de esperar, sino que aparece con un rol secundario. Es más, desde sus representaciones, los estudiantes muestran una percepción negativa de las fuentes laborales que proporcionan las industrias, a las cuales califican de riesgosas y mal remuneradas.

Con el fin de enriquecer la información que los estudiantes poseían acerca de las industrias y con la intención de observar si se producía algún cambio en las representaciones, el profesor del nivel seleccionó el tema para el desarrollo de una actividad de escritura, en el marco de su planificación semestral. Esta consideró lecturas de reportajes e información recogida de páginas web de las propias industrias, seguidas de la escritura de comentarios para recoger sus opiniones, textos que constituyen el objeto de estudio del presente trabajo. Al exponerles una visión más global y completa del tema, se buscó que los jóvenes resignificaran las representaciones de éste y afianzaran su sentido de "identidad comunitaria" (Abric, 2001).

La pregunta que guía la investigación es: ¿Qué patrones podemos identificar en el surgimiento de las habilidades de argumentación escrita, especialmente en sectores con menor acceso a la cultura letrada?

\subsection{Aproximación teórica}

Se requiere construir una mirada teórica que permita acercar dos perspectivas que tradicionalmente aparecen distanciadas. Cuando se trata de examinar las competencias de argumentación escrita encontramos abundante bibliografía con posturas lingüísticas formales. No obstante, reconociendo el valor de éstas, la intención es ampliar la perspectiva y complementarla hacia una dimensión sociocultural,

\footnotetext{
${ }^{2}$ El Sistema de Medición de la Calidad de la Educación (SIMCE) de Chile tiene el propósito de "contribuir al mejoramiento de la calidad y equidad de la educación, informando sobre los logros de aprendizaje de los estudiantes en diferentes áreas de aprendizaje del currículo nacional, y relacionándolos con el contexto escolar y social en el que estos aprenden" (Agencia de Calidad de la Educación, 2012). Para ello se aplican diferentes pruebas, destacando las de Lectura y Escritura en el área curricular de Lenguaje.
} 
es decir, abordar el discurso y su contexto de enunciación ${ }^{3}$ desde un acercamiento situado de los procesos de escritura escolares.

Planteamos que el desarrollo de las competencias de lectura y escritura implica que los sujetos se transformen en lectores y productores estratégicos, validando caminos propios desde sus construcciones colectivas e individuales. Así, a partir de la dimensión del lenguaje en uso, nos interesa analizar los textos con una perspectiva pragma-dialéctica, centrando la atención en el aspecto dialógico de la argumentación y considerándola como una discusión crítica cuyo propósito es contribuir a la resolución de una diferencia de opinión. En este sentido, priorizamos la interacción de dos o más interlocutores que buscan resolver un desacuerdo (van Eemeren, Grootendorst y Snoeck, 2006).

Partiendo de la premisa de que la argumentación cotidiana está atravesada por múltiples factores subjetivos (emociones, creencias, pasiones, etc.), uno de los objetivos es "desarrollar las herramientas para determinar en qué grado una argumentación está de acuerdo con las normas de una discusión razonable" (van Eemeren, Grootendorst y Snoeck, 2006, p.18). Para ello, no se abandona el criterio de consistencia lógica, sino que se complementa con el criterio de consistencia pragmática, que permite evaluar la razonabilidad de los argumentos en función de los contextos de interacción.

Ciertamente, la apelación a los términos de razonabilidad y de ajuste estratégico es lo que nos interesa revisar en los escritos, por cuanto esta dimensión da cuenta de la intención explícita de quien escribe y de la postura que asume respecto del fenómeno o situación en discusión (Houtlosser y van Eemeren, 2005).

Dentro de la perspectiva de ajuste estratégico, Masseron (2003) sostiene que cuando un enunciador introduce posturas contrarias a las suyas para refutarlas y reforzar su propia posición, puede plantear tres posibilidades básicas con el objetivo de desplegar su intención argumentativa e influenciar el pensamiento y/o la acción del destinatario. Estas posturas implican las siguientes estrategias (Masseron, 2003):

a) Estrategia justificativa, el enunciador justifica con uno o más argumentos una tesis explicada desde el comienzo, sin tener en cuenta si existen o no otras posturas sobre el objeto de argumentación.

b) Estrategia polémica, el enunciador contrapone su propia postura (tesis propuesta) con otras posturas opuestas (tesis y argumentos adversos) para refutarlos y concluir reforzando su propia postura.

c) Estrategia deliberativa, el enunciador no manifiesta de entrada una posición con respecto al tema, sino que proporciona elementos de juicio (datos, ejemplos, etc.) para llegar finalmente a la tesis o conclusión que constituye su propia postura. Esta postura es más sutil y manifiesta mayor grado de dominio de la argumentación.

Unida a la dimensión estratégica, se busca poner énfasis en la propiedad de la reflexibilidad, en virtud de la cual el lenguaje en uso tanto crea como refleja los contextos en los que es producido (Gee, 2005). De esta forma, se concibe el discurso como una asociación socialmente aceptada de usos del lenguaje, en palabras de Gee (2005), un conjunto de expresiones simbólicas y "artefactos de pensar", sentir, creer, valorar y actuar que puedan utilizarse para identificarse como miembro de un grupo socialmente significativo o "red social". Siguiendo esta línea, se privilegiará el término discurso argumentativo estableciendo una diferencia de foco con el concepto de texto argumentativo, por cuanto el primero se distingue por el propósito o efecto perseguido, mientras que el segundo se define por el modo de organización interna de la secuencia de informaciones que contiene. Entonces, se destaca la intención del enunciador por modificar o reforzar las opiniones de otro, pero organizando su discurso de distintas

\footnotetext{
3 Calsamiglia y Tusón (2002) definen la enunciación como el proceso cuyo "producto concreto y tangible es el enunciado" (p. 17). Este enunciado puede asumir la forma de una oración y un conjunto de ellos constituye un discurso que es emitido por un enunciador y destinado a un enunciatario.
} 
maneras, por ejemplo, a través de la narración o exposición.

En consecuencia, es posible desde el análisis de los discursos argumentativos y su red de situación, identificar las tareas de construcción. Estas tareas son realizadas por el enunciador en negociación y colaboración con otros, recurriendo a los textos que ha leído, a su conocimiento sociocultural y a las conversaciones que ha sostenido con otras personas. Por esta razón, las tareas pueden verse simultáneamente como logros cognitivos, de interacción e intertextuales.

Gee (2005) identifica seis tareas mediante las cuales se emplea el lenguaje para construir o interpretar la red de la situación, utilizando claves o señales para ensamblar significados situados de acuerdo con:

- Uso de sistemas semióticos y de conocimiento propios del tipo de comunicación utilizada (tarea construcción semiótica)

- Configuración de la realidad representada: lo que se considera como presente/ausente, real/irreal, posible/imposible (tarea construcción de mundo).

- Descripción de actividades y acciones específicas de la realidad representada en la situación de comunicación (tarea construcción de actividad).

- Representación de identidades que implican formas de actuar e interactuar, de sentir, conocer y сгеer (tarea de identidad situada socio-culturalmente).

- Definición de la naturaleza y relevancia de "bienes sociales", tales como la educación y competencia comunicativa. También se considera la concepción del estatus y poder (tarea de construcción política).

- Interacción mediatizada por los códigos verbal y no verbal que conectan el presente con el pasado y el futuro de la enunciación del discurso (tarea construcción de conexión).

Visto lo anterior y adscribiéndonos a la premisa de que desde la perspectiva lógica "no existe un modelo único y ni siquiera preferencial de un plan textual argumentativo, así como los modos textuales de la narración son muy variados y no responden a una forma específica única, los modos de la argumentación son también multiformes" (Muñoz y Mucsi, 2013), se releva la dimensión estratégica que aporta un referente básico y hace posible examinar los escritos en cuestión.

Otro aspecto que articula este estudio lo constituye el contenido del discurso, canalizado en el tema del barrio industrial de Hualpén y la identidad comunitaria de los jóvenes respecto de éste. Por lo tanto, el foco ya no se concede tanto al territorio como a las definiciones tradicionales del concepto de comunidad, sino a la identidad comunitaria que "apela a rescatar un fenómeno que define la comunidad y que actúa como elemento central en cuanto a su unificación y cohesión" (Rozas y Arredondo, 2006, p. 11).

Producto de la posmodernidad y de la globalización que incluye fenómenos complejos, como las comunidades virtuales, en el territorio pierden relevancia los elementos físicos y corporales, se pierde la relación "cara a cara", dejando paso a las "imágenes y el lenguaje". La identidad comunitaria surge, entonces, como uno de los aspectos que estabilizan a la comunidad y permiten su desarrollo y configuración como "actor social" (Rozas y Arredondo, 2006).

Por ende, la identidad comunitaria se define no como una esencia inmutable, sino como un proceso histórico permanente de construcción y reconstrucción de la comunidad, imaginada por un determinado grupo y sector cultural. Las alteraciones ocurridas en sus elementos no implican, necesariamente, que la identidad colectiva se haya perdido, sino que ha cambiado. De acuerdo con Rozas y Arredondo (2006), las diferencias culturales no obedecerían, entonces, a esencias culturales inmóviles, sino a accidentes de ubicación e historia. 
En virtud de lo expuesto, la hipótesis planteada es: Si rescatamos tempranamente el desarrollo del discurso argumentativo que los niños evidencian en la oralidad e identificamos los rasgos/patrones incipientes que caracterizan a la argumentación escrita como un proceso dialógico y un producto discursivo fuertemente anclado en la realidad, será posible avanzar hacia su dominio en la escritura. Todo lo cual tendría implicancias relevantes en la didáctica de la producción argumentativa escrita, tales como la selección de temas emergentes de la comunidad inmediata, regional o nacional, y el diseño de tareas de producción, guiadas discursiva y conceptualmente por el profesor, en un marco del lenguaje en uso.

\section{Método}

La metodología es cualitativa y corresponde al estudio colectivo de casos (Sandín, 2003) porque se examinaron cinco discursos del comentario producidos individualmente por estudiantes de sexto año básico, ${ }^{4}$ los cuales fueron seleccionados por su representatividad para ilustrar los hallazgos sobre el surgimiento de la argumentación escrita relacionadas con la hipótesis que nos proponemos describir en detalle.

Los discursos del comentario fueron producto de una tarea de escritura contemplada en la planificación semestral de un profesor del nivel, quien compartió los textos como diagnóstico para un futuro diseño didáctico.

El análisis de los discursos comprende tres niveles. El primero describe la situación en que progresó la opinión crítica, desde qué sentido avanza como proceso de interacción dialógica y como producto discursivo. El segundo nivel, desde la perspectiva pragmática, consideró la clasificación del ajuste estratégico propuesta por Masseron (2003). Enseguida, para acceder al tercer nivel, el sociocultural, empleamos la revisión de los trabajos desde las seis tareas de la red de situación descritas por Gee (2005). Adscritos a este último nivel se recogieron los indicios de cómo avanza la construcción dialéctica de la identidad comunitaria en la expresión escrita de los sujetos.

\section{Resultados y discusión}

\subsection{Primer nivel de análisis: contexto de la situación de enunciación}

La situación es actualizada, se produce en un espacio-tiempo dado y contempla una progresión de tareas: búsqueda de información, lectura y escritura desde las cuales se definen los participantes (grupo curso) investidos de sus roles y expectativas relativas al problema específico a investigar. Además de las lecturas de diversas fuentes, entre las que destacan los reportajes, los niños manejan información de la cultura de su entorno, un conjunto de datos, valores y creencias compartidas por la comunidad. Estos antecedentes proporcionan los parámetros de un escenario de discusión que garantizó el desarrollo del intercambio argumentativo escrito.

El grupo en cuestión ha tenido escasas oportunidades de ejercitar la escritura de acuerdo a la revisión de las planificaciones de nivel anterior (quinto año) realizada por el equipo de investigación. Sin embargo, lleva a cabo en forma entusiasta la búsqueda de información con apoyo de la tecnología y, sin manejo aún de las estructuras discursivas argumentativas, se elaboran los comentarios que retoman muchas de las ideas recogidas de la lectura de las fuentes consultadas, especialmente reportajes. Aclaramos que el estudio consideró pertinente recoger sólo la primera versión de los escritos, sin que mediara la retroalimentación del profesor, ni que hubiera reescritura, por cuanto nos interesaba identificar lo que los estudiantes eran capaces de producir autónomamente en un primer avance.

\footnotetext{
${ }^{4}$ Este nivel escolar es cursado por estudiantes de entre 11 y 12 años. En este estudio de caso, la muestra es mixta, compuesta por tres niños y dos niñas.
} 


\subsection{Segundo nivel: ajuste estratégico en los discursos (perspectiva pragmática)}

Los discursos fueron revisados desde la perspectiva de las estrategias usadas por sus autores. A continuación, por razones de espacio, se ejemplifica con el análisis de tres de los cinco casos:

\section{Comentario sujeto 3}

Título: Petrox, una empresa contaminante

Subtítulo: ¿Una empresa para el bien o mal del país?

La empresa Petrox filial de la Enap es una importante fuente de producción del petróleo y gas en el país. Se encuentra en nuestra comuna de Hualpén y a pesar de todos los productos que produce, funciona diariamente emanando una nube que contamina el ambiente. Esto produce un descontento en toda la comuna y sus habitantes porque le hace un mal al planeta. También está agotando la fuente de petróleo de Tierra del Fuego. La empresa contamina el aire porque no se ha preocupado lo suficiente del daño que le hace al ambiente por los residuos de gas que suelta al elaborar los productos tales como gas licuado, gasolina, solventes y bases para asfalto.

En conclusión, la empresa entrega buenos productos pero, le hace más un mal que un bien al planeta porque no se preocupa de la contaminación ambiental ya sea por el aire, por la nube que suelta, o por la protección de la tierra porque está agotando importantes recursos naturales.

Desde el título, el texto 3 (que incluye una fotografía de oleoductos de la empresa) plantea una postura crítica hacia la empresa. En el cuerpo del comentario destaca la importancia de la producción de gas para el país, pero contraargumenta calificando negativamente la contaminación que produce. Aquí el enunciador se identifica con su comuna, utiliza una estrategia polémica para defenderla. Para apoyar su contraargumento expone dos razones contundentes: contaminación y agotamiento de los recursos naturales. La polémica que abre a la discusión está ya enunciada en el título y el subtítulo, este último formulado interrogativamente. La pregunta es una forma hábil de objetar razonamientos, ya que presenta alternativas, provoca divisiones y arrastra implícitos útiles para la contraargumentación.

De los tres casos analizados, nos parece que este texto avanza con propiedad en el desarrollo argumentativo, por cuanto reconocemos en él una negación polémica hacia la empresa, expresada a través de una estructura adversativa que se enuncia a través de los conectores "a pesar de" y "pero". Según Anscombre y Ducrot (1988), estas dimensiones adversativas destacan la dimensión polifónica de determinadas estructuras lingüísticas, especialmente, de la negación polémica. Estas estructuras dan cuenta de una construcción de dos voces diferentes. El primer enunciador es el responsable de la enunciación, lo que se advierte en el título (Petrox, una empresa contaminante), seguido de una pregunta en el subtítulo, que introduce la posición de un segundo enunciador implícito en la primera oración del cuerpo del comentario. En la conclusión del comentario responde a la pregunta formulada en el subtítulo, confirmando la tesis enunciada desde el título.

\section{Comentario sujeto 4}

Título: ¿Petrox una realidad contaminada?

Subtítulo: La empresa influye en el cada día de nosotros en Hualpén.

La empresa Petrox, como todos saben, está relacionada con la extracción del petróleo en Chile. Como todos saben sus recursos, unos de los más importantes $d$

el mundo, junto con la electricidad y el agua porque producen energía y los usamos todos los días. Sin embargo queremos mostrarles las desventajas de esta empresa, primero es un recurso que no durará para siempre pero el ser humano no se da cuenta de esto. También al ocuparlo diariamente no pensamos en los efectos colaterales. Lo malo de la extracción del petróleo es que 
contamina demasiado la atmósfera de la tierra y esto mata la flora y fauna del ambiente chileno, esto también afecta a otros países porque a veces el petróleo se derrama en el mar.

En conclusión, Petrox aporta al país buen petróleo, pero a un costo muy grande, debemos estudiar como disminuir los efectos negativos de esta empresa de Hualpén.

El texto del alumno incluye dos fotografías: una de las chimeneas de la empresa con las nubes de humo y otra del área de la bahía con las chimeneas de la empresa contaminando.

En este discurso se usa la modalidad interrogativa, esta vez en el título, donde la pregunta que contiene un implícito es de inmediato respondida por la aseveración del subtítulo que contraargumenta respecto de los efectos de la contaminación en la comuna, posición con la que el enunciador se identifica e incluye.

Las razones que se esgrimen para fundamentar la opinión crítica tienen que ver nuevamente con el agotamiento de los recursos naturales y la contaminación. La estrategia usada es deliberativa, la posición del enunciador se plantea en el desarrollo del comentario, donde reconoce la importancia del petróleo como energía, pero destaca los efectos nocivos de su extracción. A nuestro juicio, en el desarrollo de este texto hay mayor dominio de la argumentación por cuanto no predispone al destinatario a una posición absolutamente negativa del tema, sino que lo plantea como la consecuencia de un problema para el que debe buscarse solución, postura que se manifiesta claramente en la conclusión.

\section{Comentario sujeto 5}

Título: Enap: veneno para la ciudad

Subtítulo: Vecinos molestos por enfermedades y olores de azufre en Hualpén

La empresa Enap de petróleo se creó en 1950 y entrega muchos productos pero lleva alrededor de 64 años contaminando nuestra comuna. El 13 y 16 de octubre 2015 la empresa despidió a uno de sus trabajadores tras los episodios de contaminación por azufre en Hualpén. El azufre es uno de los contaminantes que emana de la empresa. ¿Qué es el azufre? Es un elemento químico muy dañino para la salud. Tras estos hechos la municipalidad de Hualpén demandó a la empresa Enap por la contaminación y los malos olores que enferman a la población.

En conclusión, podemos señalar que si la empresa Enap sigue contaminando nuestra ciudad, tal como lo señaló la Municipalidad la empresa puede cerrarse y se acabaría la contaminación.

El título del comentario explicita de inmediato la posición crítica del enunciador con una aseveración no discutible, expuesta con mucha fuerza al establecer la analogía entre los términos "Enap/veneno". Luego, desde el subtítulo, la opinión crítica se fundamenta en un hecho específico, el despido de un trabajador, ocurrido debido a la contaminación por azufre que afecta a la población y a los trabajadores de la empresa. El comentario no entrega información suficiente para aclarar la causa del despido del trabajador: ¿el azufre lo afectó a él como trabajador o una acción del trabajador provocó mayores emanaciones de azufre hacia la población?

Luego, se describe una intervención de la municipalidad como organismo público que se hace cargo de la contaminación de la comuna. La posición del enunciador es clara, si bien al inicio del desarrollo del discurso asume que la empresa entrega "muchos productos", reconoce que provoca un problema grave de contaminación. Su postura se refrenda en la conclusión, donde confía de manera ingenua en que la municipalidad dará solución al problema de la contaminación. 
Cabe destacar que este comentario se complementó con dos muy buenas fotografías, una de un trabajador manipulando un cierre de oleoducto y la segunda de un hombre con máscara de gas en el suelo, presa de un ambiente contaminado.

\subsection{Tercer nivel de análisis (sociocultural): los discursos y la red de situación}

El análisis buscó recoger los indicios sobre cómo el lenguaje, simultáneamente, refleja y construye la situación en la que se empleó. Consideramos como base el modelo de análisis de Gee (2005), que consiste en evidenciar las señales o claves de la "red de situación" a partir de seis tareas de construcción.

1) Construcción semiótica: En los comentarios, los sistemas comunicativos activados son básicamente dos: el verbal y las imágenes, ambos potenciados por el uso tecnológico. Tanto los resultados de las lecturas como los avances de la escritura se sistematizan en un blog organizado por el docente.

Los discursos finales son breves y las fotografías incluidas enfatizan las ideas más relevantes; mientras mayor es el nivel polémico alcanzado en el código verbal, más evidente es esta posición desde la fotografía que lo apoya. Así, destacamos los textos 4 y 5 . El primero presenta dos fotografías, una en la que se observan chimeneas de una empresa que contamina y otra que muestra una vista aérea de la caleta de Lenga inundada con el humo de la contaminación.

El texto 5 presenta también dos fotografías: el cierre de un oleoducto por la acción humana y un hombre en el suelo, víctima de la acción contaminante, recurriendo a una máscara de oxígeno para respirar. Queda claro en los ejemplos analizados que los estudiantes reconocen la importancia de las imágenes como complemento de lo expresado verbalmente, puesto que realizan un ensamblaje entre ambos sistemas para apoyar la postura crítica que afianzan. De esta forma, observamos un progreso en la representación de identidad comunitaria que se estaría conformando en los sujetos como actores sociales, desde los códigos semióticos básicos de la postmodernidad: el lenguaje y las imágenes (Rozas y Arredondo, 2006).

2) Construcción del mundo. Los comentarios recogen la nueva información a la que los estudiantes han tenido acceso sobre las industrias. Han ampliado información del mundo que los rodea y, apoyados en la interacción comunicativa grupal, reconstruyen las representaciones de su realidad. Algunos de ellos (casos 3, 4 y 5) abordan una postura crítica que identifica problemas de esta realidad y, al mismo tiempo, plantean necesidades y posibles soluciones, desde el estado de situación presente con proyecciones al futuro. En este sentido, observamos claves de cómo los jóvenes toman conciencia respecto al tema territorial que desconocían y frente al cual no tenían una postura que los identificara.

3) Construcción de actividades. Unida a la dimensión anterior, con foco en las actividades, la postura crítica de la realidad que se asume, lleva a los estudiantes a describir medidas traducidas en tareas concretas que debería considerarse en el mediano y largo plazo. Es decir, la construcción de su mundo comunitario inmediato ha comenzado a variar, es problematizado a partir de la información recogida y toman conciencia de que tanto los problemas como las posibles soluciones dependen de un anclaje en la acción humana.

4) Construcción de identidad socio-culturalmente situada. La identidad de los estudiantes como sujetos culturalmente situados, claramente evidenciada en cuatro de los cinco casos (exceptuando el primero), comienza a afianzarse al establecer relaciones con su entorno, asumiendo una postura que los inscribe, al menos discursivamente, dentro de valores ecológicos y de protección del medio ambiente. Esta actitud valórica, reflejada en el uso del lenguaje situado, es la que dará fuerza a la dimensión estructural formal del discurso, que avanza todavía intuitivamente hacia el manejo de la modalidad argumentativa. Y declaramos "intuitivamente" porque a estas alturas no ha mediado una intervención metodológica que ponga énfasis en los aspectos lógico-estructurales del texto argumentativo. 
5) Construcción política. El proceso anterior de demarcación de su identidad sitúa a los sujetos, además, hacia una postura de construcción política. Reconocen el ambiente como un bien social y visualizan la necesidad de equilibrar la producción industrial con su protección. Identifican un conflicto entre las industrias y el medio ambiente, los poderes que se conjugan en la toma de decisiones y se reconocen como sujetos de un territorio en tensión. Entonces, la experiencia del estudiante y su entorno comunitario surge como punto de partida en la construcción social crítica (Giroux, 1998). En este sentido, se comienza a tomar conciencia de los poderes ideológicos y económicos que subyacen a las tensiones descubiertas.

6) Construcción de conexión. Las tareas de conexión nos invitan a reconocer señales en la forma en que los estudiantes se proyectarán hacia interacciones argumentativas futuras, tanto desde las perspectivas verbales como de las imágenes implicadas en la estructura semiótica que genera su texto.

Esta última tarea, a nuestro juicio, engloba a todas las anteriores, por cuanto los jóvenes son capaces de establecer las relaciones intertextuales que los relacionan con su entorno y las tensiones en la comunidad sobre las que se han informado y escrito con intenciones discursivas de avance y progresión social. El grupo ha resignificado su realidad e impugna críticamente aspectos del sistema observados.

\section{Conclusiones}

Reconocemos, en los casos revisados el inicio del proceso de argumentación en las opiniones críticas observadas en los comentarios elaborados por los estudiantes. Los comentarios progresaron en un escenario de aprendizaje organizado que consideró variables culturales y pedagógicas, movilizando naturalmente a los sujetos hacia la escritura argumentativa. Por tanto, desde la situación de enunciación, los estudiantes -con un propósito de escritura claro- visualizaron a sus lectores potenciales entre sus propios pares y vecinos, a los que afecta el problema de las emanaciones contaminantes de las industrias de la comuna.

De acuerdo con este hallazgo, a partir de la perspectiva pedagógica, para guiar la producción escrita argumentativa en el aula es preciso activar secuencial y progresivamente las tareas de lectura y escritura. El desarrollo de la argumentación requiere de un enunciador informado sobre el tema objeto de comentario, que le permita plantear su postura en diálogo con otras. En los casos analizados, se observa que los estudiantes manejaban antecedentes de las industrias desde la cultura popular de su entorno. Luego, en la mediación didáctica del profesor del nivel, se intencionó la ampliación de la información a través de la búsqueda en la red, donde los sujetos encontraron reportajes periodísticos y páginas web oficiales de las industrias de la comuna.

Visto lo anterior, en los discursos analizados puede observarse un patrón de organización que evidencia el avance hacia lo argumentativo: la presentación de nueva información acerca de las industrias y sus características, a la que se contrapone la postura de los autores, quienes demuestran una toma de conciencia frente al tema medioambiental. De este modo, se evidencia una ampliación de la información del mundo que los rodea, según la cual los jóvenes se vuelven conscientes de la situación ambiental desde una postura identitaria que se afianza a través de la escritura.

En síntesis, postulamos que cuando el currículum nacional privilegia una primera aproximación didáctica con énfasis en la lógica de la argumentación (Mineduc, 2016), se pierde un número importante de factores contextuales, situacionales, emocionales, aspectos que afectan la conducta y el resultado del intercambio argumentativo. En consecuencia, es importante aprovechar que este tipo de discurso surge tempranamente, aun en contextos con escaso desarrollo de las prácticas de escritura, cuando se realizan ejercicios iniciales de argumentación fuertemente anclados a la realidad y al lenguaje en acción. 


\section{Referencias}

Abric, J. C. (2001). Prácticas sociales y representaciones. México: Coyoacán.

Agencia de Calidad de la Educación. (2012). ¿Qué es el SIMCE? Recuperado de http://www.agencia educacion.cl/evaluaciones/que-es-el-simce/

Agencia Calidad de la Educación. (2015). Síntesis resultados de aprendizaje 6o. Básico. SIMCE 2014 escritura. Recuperado de http://archivos.agenciaeducacion.cl/resultados-2014/Sintesis Resultados 6B Escritura 2014.pdf

Agencia de Calidad de la Educación. (2016). Resultados de aprendizaje de escritura 6o. básico. Recuperado de http://archivos.agenciaeducacion.cl/Resultados Nacionales Escritura2015 6basico.pdf

Anscombre, J. C. y Ducrot, O. (1988). La argumentación en la lengua. Madrid: Gredos.

Calsamiglia, H. y Tusón, A. (2002). Las cosas del decir. Manual de análisis del discurso. Barcelona: Ariel.

Gee, J. P. (2005). La ideología en los discursos. Madrid: Morata.

Giroux, H. (1998). La escuela y la lucha por la ciudadanía. Pedagogía crítica de la época moderna. Buenos Aires: Siglo XXI.

Houtlosser, P. y Van Eemeren, F. (2005). Une vue synoptique de l'approche pragma-dialectique, [Una visión sinóptica del enfoque pragma-dialéctico] en M. Doury y S. Moirand (Eds.). L'argumentation aujourd'hui. Positions théoriques en confrontation [La argumentación hoy. Posiciones teóricas en confrontación], (pp. 45-75). París: Presses Sorbonne Nouvelle.

Masseron, C. (2003). Le déficit syntaxique dans les copies argumentatives. Hypothèses et propositions de travail [El déficit sintáctico en las copias argumentativas. Hipótesis y propuestas de trabajo]. Le français aujourd'hui, 2(141), 83-97. doi:10.3917/lfa.141.0083

Mineduc (2016). Programa de estudio 10. Medio Lengua y Literatura. Santiago de Chile: Ministerio de Educación.

Muñoz, N. y Musci, M. (2013). Manual de lectura y escritura argumentativas. Aproximaciones teóricas y actividades prácticas. Río Gallegos: Universidad Nacional de la Patagonia Austral.

Rozas, G. y Arredondo, J. (Comp.)(2006). Identidad, comunidad y desarrollo. Santiago de Chile: LOM.

Sandín, M. P. (2003). Investigación cualitativa en educación. Madrid: McGraw Hill.

Van Eemeren, F., Grootendorst, R. y Snoeck, F. (2006) Argumentación: análisis, evaluación, presentación. Buenos Aires: Biblos. 